\title{
PREVALENSI MIOMA UTERI BERDASARKAN UMUR DI RSUP PROF. DR. R. D. KANDOU MANADO
}

\author{
${ }^{1}$ Sabrianti Pasinggi \\ ${ }^{2}$ Freddy Wagey \\ ${ }^{2}$ Max Rarung
}

\author{
${ }^{1}$ Kandidat skripsi Fakultas Kedokteran Universitas Sam Ratulangi Manado \\ ${ }^{2}$ Bagian Obstetri dan Ginekologi Fakultas Kedokteran Universitas Sam Ratulangi Manado \\ Email: spasinggi11_074@yahoo.com
}

\begin{abstract}
Myoma uteri is a benign tumor of the uterine. Insidence of myoma uteri at $20 \%$ $30 \%$ of all women and continues to increase. The second most common gynecological tumors in Indonesia. Commonly found in women of reproductive age and only $10 \%$ of myoma uteri is still growing after menopause. Approximately $60 \%$ asymptomatic and almost $50 \%$ are found incidentally on gynecologic examination. Objective: to determine the age prevalence of uterine myomas compared with other gynecological tumors in the Prof. Dr R. D. Kandou Hospital Manado.Methods:Retrospective descriptive study using medical records. Sample of this study is 401 cases of gynecological tumors, 127 of them is cases of myoma uteri in period of July ${ }^{\text {st }} 2013-J u l y ~ 1^{\text {st }} 2014$. The data analysis is univariate analysis.Results and Conclusion: The results of medical records in period July $1^{\text {st }} 2013-J u l y ~ 1^{\text {st }} 2014$, myoma uteri is the second largest gynecological tumors (31.7\%). Based on 127 cases, the suffered most from of myoma uteri is the age between $41-50$ years (56.7\%). The highest prevalence of uterine myoma in the age between $41-50$ years (48.9\%).
\end{abstract}

Keywords: gynecological tumors, myoma uteri, prevalence, age

\begin{abstract}
Abstrak: Mioma uteri adalah tumor jinak pada uterus. Insidensinya sekitar 20\%-30\% dari seluruh wanita dan terus mengalami peningkatan. Tumor ginekologi kedua terbanyak di Indonesia. Umumnya ditemukan pada wanita usia reproduksi dan hanya 10\% mioma uteriyang masih tumbuh setelah menopause. Kira-kira 60\% asimtomatik dan hampir 50\% ditemukan secara kebetulan pada pemeriksaan ginekologik.Tujuan Penelitian: Untuk mengetahui prevalensi mioma uteri berdasarkan umur dibandingkan dengan tumor ginekologi lainnya di RSUP Prof. Dr. R. D. Kandou Manado.Metode Penelitian:Desain deskriptif retrospektif menggunakan catatan rekam medik. Sampel pada penelitian ini adalah 401 kasus tumor ginekologi, 127 di antaranya kasus mioma uteri periode 1 Juli 2013-1 Juli 2014. Analisis data yang digunakan adalah analisis univariat.Hasil dan Kesimpulan:Darihasil catatan rekam medik pada periode 1 Juli 2013-1 Juli 2014, mioma uteri merupakan tumor ginekologi kedua terbanyak (31,7\%). Dari 127 kasus yang paling banyak menderita mioma uteri adalah kelompok umur 41-50 tahun (56,7\%). Prevalensi mioma uteri tertinggi pada kelompok umur 41-50 tahun (48,9\%).
\end{abstract}

Kata kunci: tumor ginekologi, mioma uteri, prevalensi, umur

Kesehatan reproduksi wanita memberikan pengaruh yang besar danberperan penting terhadap kelanjutan generasi penerus bagi suatu negara serta merupakan parameter kemampuan Negara dalam menyelenggarakan pelayanan kesehatan terhadap masyarakat.

Salah satu masalah pada kesehatan reproduksi wanita adalah ditemukannya 
mengalami peningkatan. ${ }^{2}$ Mioma uteri adalah tumor jinakotot polos yang terdiri dari sel-sel jaringan otot polos, jaringan ikat fibroid dan kolagen. Beberapa istilah untuk mioma uteri antara lain fibromioma, miofibroma, leiomiofibroma, fibroleiomioma, fibroma, dan fibroid. ${ }^{3}$

Mioma uteri belum pernah ditemukan sebelum terjadinya menarche dan setelah menopause hanya kira-kira $10 \%$ mioma yang masih tumbuh, sebagian besar ditemukan pada wanita usia reproduksi sebanyak 20-25\%. ${ }^{4,5}$ Diperkirakan insiden mioma uteri sekitar 20\%-30\% dari seluruh wanita. $^{6}$

Studi prevalensi yang dilakukan di delapan negara pada tahun 2009 melaporkan kejadian mioma uteri sebanyak 4,5\% pada wanita Inggris, 4,6\% Perancis, 5,5\% Kanada, 6,9\% Amerika Serikat, 7\% Brazil, 8\% Jerman, 9\% Korea, dan 9,8\% di Italia.Prevalensi mioma uteri mengalami peningkatan hingga $14,1 \%$ pada kelompok umur 40 tahun ke atas. Rata-rata mioma uteri didiagnosis pada rentang usia 33,5 hingga 36,1 tahun. ${ }^{7}$

Mioma uteri merupakan tumor jinak terbanyak pada wanita dan merupakan indikasi histerektomi tersering di Amerika Serikat. $^{7}$ Tercatat sebanyak $39 \%$ dari 600.000 histerektomi yang dilakukan di Amerika Serikat tiap tahunnya.Studi yang dilakukan di Amerika Serikat dengan teknik random sampling pada wanita usia 35-49 tahun menemukan bahwa 60\% kasus terjadi pada usia 35 tahun dan meningkat sebanyak $80 \%$ di usia 50 tahun pada wanita Afro-Amerika. Sedangkan pada wanita Kaukasian insiden mioma uteri mencapai $40 \%$ pada usia 35 tahun dan $70 \%$ pada usia 50 tahun. $^{8}$

Resiko mioma uteri meningkat seiring dengan peningkatan umur. Penelitian di Italia (2004) melaporkan 73 kasus mioma uteri dari 341 wanita pada usia 30-60 tahun dengan prevalensi 21,4\%. Di India (2006) terdapat 150 kasus mioma uteri, 77 kasus (51\%) terjadi pada wanita usia 40-49 tahun dan 45 kasus (30\%) terjadi pada wanita umur lebih dari 50 tahun. ${ }^{9}$ Di Nigeria (2014) melaporkan prevalensi mioma uteri sebanyak 44,41\% pada wanita dengan usia 31-40 tahun dengan usia rata-rata terjadi pada wanita usia 30,5 tahun. ${ }^{10}$

Jumlah kejadian penyakit ini diIndonesia menempati urutan kedua setelahkanker serviks. Mioma uteri ditemukan pada 2,39\%-11,7\% pada semua penderita ginekologi yang dirawat, sering ditemukan pada wanita nulipara atau kurang subur daripada wanita yang sering melahirkan. ${ }^{6}$ Prevalensi mioma uteri di Surabaya dan Riau masing-masing sebanyak 10,03\% dan 8,03\% dari semua pasien ginekologi yang dirawat. ${ }^{11,12}$

Data di RSUP Prof. Dr. R.D. Kandou Manado menyatakan bahwa mioma uteri menempati urutan pertama penyakit ginekologi tersering. Sebanyak 408 kasus mioma uteri ditemukan pada tahun 20112013, dengan rincian 112 kasus (16\%) pada tahun 2011, 168 kasus (25\%) pada tahun 2012, dan 128 kasus $(25,6 \%)$ pada tahun 2013. ${ }^{13,14,15}$

Sekitar dua per tiga kasus mioma uteri asimtomatik dan hampir setengah dari kasus ditemukan secara kebetulan pada pemeriksaan ginekologik.Diperkirakan hanya $20-50 \%$ mioma saja yang menimbulkan gejala klinik seperti menoragia, ketidaknyamanan pelvis, serta disfungsi reproduksi. Sehingga tidak ada korelasi antara besarnya mioma dengan keluhan yang muncul., ${ }^{6,16,17}$

Berdasarkan uraian di atas, dapat diketahui bahwa mioma uteri termasuk dalam neoplasma jinak ginekologi asimtomatik tersering dengan insiden satu dari empat wanita selama masa reproduksi aktif. Oleh karena itu, wanita usia subur diharapkan partisipasinya untuk melakukan pemeriksaan ginekologi secara teratur agar terhindar dari kejadian tumor jinak ini serta penegakkan diagnosis dan penanganan dini dapat dilakukan.

RSUP Prof. Dr. R. D. Kandou merupakan rumah sakit pendidikan yangmenjalin kerjasama dengan Universitas Sam Ratulangi Manado. Sebagairumah sakit rujukan di Manado dan sekitarnya, melayani persoalan- 
persoalankesehatan dari segala aspek lapisan masyarakat dan memilikijumlah kasus mioma uteri yang cukup tinggi. Berdasarkan pada kenyataan diatas, maka hal ini mendorong peneliti untuk mengetahui lebih jauh mengenai prevalensi mioma uteri berdasarkan umur dibandingkan dengan tumor ginekologi lainnya di RSUP Prof. Dr. R. D. Kandou Manado.

\section{METODE PENELITIAN}

Jenis penelitian yang dilakukan adalah penelitian deskriptif dengan pendekatan retrospektif. Penelitian ini dilakukan di bagian Obstetri dan Ginekologi RSUP Prof. Dr. R.D. Kandou pada bulan Oktober sampai Desember 2014. Populasi dalam penelitian ini adalah semua pasien rawat inap umur 21 hingga lebih dari 60 tahun di bagian Obstetri dan Ginekologi RSUP Prof. Dr. R. D. Kandou Manado selama periode 1 Juli 2013-1 Juli 2014 yang didiagnosis mioma uteri. Sampel pada penelitian ini adalah jumlah populasi (total sampling).

Pengumpulan data dilakukan dengan memanfaatkan data sekunder dari catatan di rekam medik dan buku register instalasi rawat inap Bagian Obstetri Ginekologi RSUP Prof. Dr. R.D. Kandou periode 1 Juli 2013- 1 Juli 2014. Data kemudian diseleksi dan dikumpulkan dengan mencatat variabel yang diperlukan yang kemudian dikelompokkan menurut pengelompokkan data.

Analisis datayang dilakukanyaitu analisis univariat untuk mengetahui distribusi frekuensi tiap variabel. Adapun variabelyang diteliti antara lain kejadian mioma uteri, kejadian tumor ginekologi lainnya, umur pasien mulai dari 21 tahun hingga lebih dari 60 tahun yang dibagi ke dalam lima kelompok umur. Kemudian dilakukan perhitungan untuk mengetahui prevalensi mioma uteri, di mana jumlah kasus mioma uteri per kelompok umur dibagi jumlah tumor ginekologi pada kelompok umur yang sama kemudian dipersentase.

\section{HASIL DAN BAHASAN PENELITIAN}

Berdasarkan hasil penelitian retrospektif,tercatat jumlahkasus berusia 21 sampai $>60$ tahun yang terdiagnosis menderita tumor ginekologi di Bagian ObstetriGinekologi RSUP Prof. Dr. R.D. KandouManado periode 1 Juli 2013 - 1Juli 2014sebanyak401 kasus. Mioma uteri merupakan tumor ginekologi kedua tersering sebanyak 127 kasus (31,7\%) (Tabel 1).

Tabel 1. Distribusi kejadian mioma uteri

\begin{tabular}{lcc}
\hline Tumor ginekologi & $\mathbf{n}$ & $\mathbf{\%}$ \\
\hline Adenomiosis & 4 & 1 \\
Ca cerviks & 1 & 0,2 \\
Ca corpus & 2 & 0,5 \\
Ca endometrium & 6 & 1,5 \\
Ca ovarium & 15 & 3,7 \\
Ca serviks & 82 & 20,4 \\
Hiperplasia endometrium & 2 & 0,5 \\
Kista ovarium & 129 & 32,2 \\
Koriokarsinoma & 4 & 1 \\
Mioma uteri & 127 & 31,7 \\
Polip serviks & 2 & 0,5 \\
Tumor padat ovarium & 27 & 6,7 \\
Total & 401 & 100 \\
\hline
\end{tabular}

Dari data rekam medis, ditemukan kasus non mioma uteri (tabel 1) sebanyak 274 kasus $(68,3 \%)$ dan kasus mioma uteri sebanyak 127 kasus (31,7\%). Hal ini sesuai dengan Norwitz(2007) yang menyatakan hampir sepertigakasus ginekologi merupakan mioma uteri,dengan angka estimasi mioma uteri $25-30 \% .^{9}$

Dari tabel 2, diperoleh hasil mioma uteri terbanyak pada kelompok umur 41-50 tahun berjumlah 72 kasus (56,7\%) dan terendah pada usia 20-30 tahun, di mana tidak ada kejadian mioma uteri yg dilaporkan pada kelompok usia ini serta pada kelompok umur $>60$ tahun sebanyak satu kasus atau $0,8 \%$. Hasil penelitian ini sesuai dengan penelitian Kurniasari di RSUD Dr. Moerwadi Surakarta yang menemukan bahwa frekuensi penderita mioma uteri terbanyak pada kelompok umur 41-50 tahun yaitu $61,40 \%{ }^{18}$ 
Penelitian Ginting di RSUD Dr. Pirngadi Medan juga menemukan sebanyak 59,9\% mioma uteri ada pada kelompok umur 4049 tahun. ${ }^{12}$ Sejalan dengan hal tersebut, penelitian Muzakir di RSUD Arifin Achmad Riau melaporkan bahwa frekuensi mioma uteri terbanyak pada kelompok umur 45-49 tahun (45,94\%). ${ }^{19}$ Penelitian sebelumnya di RSUP Prof. Dr. R.D. Kandou Manado oleh Pratiwi, juga menemukan frekuensi tertinggi mioma uteri yaitu pada kelompok umur 35-49 tahun sebanyak $69,1 \%$, , sehingga dapat diambil kesimpulan bahwa hasil penelitian berada dalam rentang umur yang sama.

Dari 127 kasus (tabel 2), ditemukan bahwa rata-rata mioma uteri di RSUP Prof. Dr. R.D. Kandou Manado terdiagnosis pada umur 44,47 tahun dengan usia minimum yaitu 31 tahun dan usia maksimum 61 tahun.Hasil ini hampir sama dengan penelitian Fradhan yang menemukan usia rata-rata pasien mioma uteri yaitu 43,3 tahun. ${ }^{20}$

Tabel 2. Distribusi kejadian mioma uteri berdasarkan umur

\begin{tabular}{lcc}
\hline Umur & $\mathbf{n}$ & $\mathbf{\%}$ \\
\hline 21-30 tahun & 0 & 0 \\
31-40 tahun & 35 & 27,6 \\
41-50 tahun & 72 & 56,7 \\
51-60 tahun & 19 & 15 \\
$>60$ tahun & 1 & 0,8 \\
Total & 127 & 100 \\
\hline
\end{tabular}

Wiknjosastro menyatakan bahwa frekuensi kejadian mioma uteri paling tinggi antara usia 35 - 50 tahun yang mendekati angka 40\%, jarang ditemukan pada usia di bawah 20 tahun. Hal ini disebabkan karena pada usia sebelum menarche kadar estrogen rendah, dan meningkat pada usia reproduksi serta akan turun pada usia menopause. ${ }^{21}$

Tabel 3 menunjukkanprevalensi tertinggi mioma uteri pada kelompok umur 41-50 tahun sebanyak 48,9\%dan terendah pada kelompok umur $>60$ tahun sebanyak 3,4 \%. Temuan ini lebih rendah dari penelitian Joedosaputro yang mengatakan prevalensi mioma uteri yang ditemukan wanita menopause sebesar $10 \% .{ }^{22}$ Suhatno juga menyatakan bahwa mioma uteri ditemukan sekitar 20\% pada wanita usia reproduksi dan sekitar $40 \%-50 \%$ pada wanita usia di atas 40 tahun. ${ }^{23} \mathrm{Hal}$ ini menunjukkan bahwa kejadian tumor ini meningkat pada usia reproduksi. Manuaba (2009) mengemukakan bahwaseiring dengan dimulainya usia reproduksi,maka mulai terjadi berbagai masalah yangberhubungan dengan kesehatan reproduksiatau alat reproduksi. ${ }^{1}$

Tabel 3. Prevalensi mioma uteri berdasarkan umur

\begin{tabular}{|c|c|c|c|c|c|}
\hline \multirow[t]{2}{*}{ Umur } & \multicolumn{2}{|c|}{$\begin{array}{c}\text { Mioma } \\
\text { uteri }\end{array}$} & \multicolumn{2}{|c|}{$\begin{array}{c}\text { Non } \\
\text { mioma } \\
\text { uteri }\end{array}$} & \multirow[t]{2}{*}{$\begin{array}{c}\text { Prevalens } \\
\text { (\%) }\end{array}$} \\
\hline & $\mathrm{n}$ & $\%$ & $\mathrm{n}$ & $\%$ & \\
\hline $21-30$ & 0 & 0 & 35 & 12,8 & 0 \\
\hline $31-40$ & 35 & 27,6 & 66 & 24,1 & 34,6 \\
\hline $41-50$ & 72 & 56,7 & 75 & 27,4 & 48,9 \\
\hline $51-60$ & 19 & 15 & 70 & 25,5 & 21,3 \\
\hline$>60$ & 1 & 0,8 & 28 & 10,2 & 3,4 \\
\hline Total & 127 & 100 & 274 & 100 & \\
\hline
\end{tabular}

Ada beberapa alasan yang mendasari peningkatan jumlah mioma uteri yang terdiagnosis pada usia $>40$ tahun antara lain karena peningkatan pertumbuhan atau peningkatan gejala yang dirasakan dari mioma yang telah ada jauh sebelum gejala tersebut dirasakan oleh penderita. Selain itu, pada usia ini kesediaan penderita untuk

\begin{tabular}{lccccc}
\hline & $\mathrm{N}$ & Min & Max & Mean & SD \\
\hline $\begin{array}{l}\text { Umur } \\
\text { Pasien }\end{array}$ & 127 & 31 & 61 & 44.47 & 6.075 \\
\hline
\end{tabular}

datang ke pusat pelayanan kesehatan untuk menjalani prosedur pembedahan ginekologi lebih besar sehingga mioma uteri ini dapat terdiagnosis. Hipotesis lain menyatakan bahwa faktor hormonal yang disebabkan oleh stimulasi hormon estrogen selama 20 sampai 30 tahun memuncak pada usia $>40$ tahun. $^{24}$ 
Peningkatan umur merupakan faktor resiko terjadinya mioma uteri. Hal ini disebabkan karena pertumbuhan dan perkembangan mioma uteri disebabkan oleh stimulasi hormon estrogen yang disekresikan oleh ovarium. Mioma uteri jarang timbul pada usia sebelum menarche dan sesudah menopause, tumbuh dengan lambat dan sering terdeteksi pada usia dekade keempat. ${ }^{25}$

Berdasarkan hasil penelitian di atas, diketahui bahwa mioma uteri paling sering terjadi pada kelompok umur 41-50 tahun atau dekade keempat. Pengaruh paparan hormon estrogen terhadap kejadian mioma uteri berjalan bertahap dan berkembang seiring peningkatan usia, di mana terdapat perbedaan pada setiap individu. Hal inilah yang mengakibatkan terdapat variasi distribusi kejadian mioma uteri pada beberapa kelompok umur. Namun onset perubahan seluler pada mioma uteri paling sering termanifestasi pada usia 40-an dan menurun pada usia lebih tua, walaupun proses perkembangan perubahan seluler ini sudah berlangsung sejak usia reproduksi awal.

\section{SIMPULAN}

Dari hasil penelitian yang dilakukan di Bagian Obstetri \& Ginekologi RSUP Prof Dr. R.D. Kandou Manado periode 1 Juli 2013-1 Juli 2014, dapat diambil kesimpulan bahwa jumlah pasien mioma uteri adalah 127 pasien (31,7\%) dari 401 kasus tumor ginekologi.Angka kejadian mioma uteri terbanyak pada kelompok umur 41-50 tahun sebanyak 72 kasus (56,7\%).Prevalensi mioma uteri tertinggi pada kelompok umur 41-50 tahun sebanyak $48,9 \%$.

\section{UCAPAN TERIMA KASIH}

Ucapan terima kasih disampaikan pada dosen pembimbing dan penguji, yang telah memberikan masukan, saran, dan kritik serta kepada semua pihak yang baik secara langsung maupun tidak langsung telah membantupenulis sehingga dapat menyelesaikan penelitian ini.

\section{DAFTAR PUSTAKA}

1. Manuaba IBG. Memahami Kesehatan Reproduksi Wanita. Edisi 2. Jakarta: PenerbitEGC; 2009.

2. Schwartz S.I. Intisari Prinsip - Prinsip IlmuBedah. Edisi 6.Jakarta: Penerbit EGC; 2000.

3. Hadibroto, Budi R. Mioma Uteri. Majalah Kedokteran Nusantara, Volume 38, No. 3, September 2005.

4. Guyton AC. Fisiologi Kedokteran.Edisi 11. Jakarta: Penerbit EGC.2007.

5. Adriaansz G. In: Prawirohardjo S, Wiknjosastro $\mathrm{H}$, Sumapraja $\mathrm{S}$, editorts. Ilmu Kandungan (EdisiKetiga). Jakarta: Yayasan Bina PustakaSarwono, 2011; p.12, 274278.

6. Baziad A. Endokrinologi Ginekologi. Edisi ketiga. Jakarta: Media Aesculapius FKUI.2008:2015-23.

7. Zimmermann et al. Prevalence, symptoms, and management of uterine fibroids: an international internet-based survey of 21,746 women. BioMed Central Women., June 2012:1-2.

8. Advancing Minimally Invasive Ginecology (AAGL) Practice Report: Practice Guidelines for The Diagnosis and Management of Submucou Leiomyomas. Elsevier. Journal of Minimally Invasive Ginecology. Vol 19. No 2. March/April 2012:152-55.

9. Pratiwi, Lilis. Hubungan usia reproduksi dengan kejadian mioma uteri di RSUP Prof. Dr. R. D. Kandou Manado [Skripsi]. Manado:FKUUnsrat;2012.

10.Odokuma EI. Age prevalence of leiomyoma uteri: a histopathologic study. Sciencedomain. British Journal of Applied Science \& Technology. Vol 4. April 2014: 2395-99.

11.Lilyani, D.I. Hubungan faktor resiko dan kejadian mioma uteri di RSUD Tugurejo Semarang [Skripsi]. Semarang:FKU-Universitas Muhammadiyah Semarang;2012.

12.Ginting LYB. Karakteristik penderita mioma uteri yang dirawat inap RSUD Dr. Pirngadi Medan tahun 2009-2011 [Skripsi]. Medan:FKM-USU;2012.

13.Bagian Obstetri Ginekologi RSUP Dr. Prof. R. D. Kandou Manado. Tabel 10 Kasus Ginekologi Terbanyak Pada 
Tahun 2011. Manado. 2012

14. Bagian Obstetri Ginekologi RSUP Dr. Prof.

R. D. Kandou Manado. Tabel 10

Kasus Ginekologi Terbanyak Pada

Tahun 2012. Manado. 2013

15. Bagian Obstetri Ginekologi RSUP Dr. Prof.

R. D. Kandou Manado. Tabel 10

Kasus Ginekologi Terbanyak Pada

Tahun 2013. Manado. 2014

16.Benson R. Buku Saku Obstetri dan Ginekologi. Edisi 6. Jakarta: Penerbit EGC, 2008.

17.Hillegas KB. Gangguan Sistem Reproduksi Perempuan. Dalam: Price SA, Wilson LM. Patofisiologi. Edisi Keenan, vol. 2. Alih Bahasa Pendit BU, Hartanto $\mathrm{H}$, Wulansari P, Mahanani DA. Jakarta: Penerbit EGC.2006:12761310.

18.Kurniasari T.Karakteristik mioma uteri di RSUD Dr. Moewardi Surakarta Periode Januari 2009-Januari 2010 [Skripsi]. Surakarta:FKU-Universitas Sebelas Maret Surakarta;2010.

19.Muzakir. Profil Penderita Mioma Uteri di RSUD Arifin Achmad Provinsi Riau Periode 1 Januari-31 Desember 2006. [Skripsi]. Pekanbaru:FKUUniversitas Riau;2008.

20.Fradhan P, Acharya N, Kharel B et-al. Uterine Myoma: A Profile of Nepalese Women. N.J. Obstet.
Gynaecol. Vol. 1/No. 2. 2006:47-50.

21.Prawirohardjo S, Wiknjosastro $\mathbf{H}$, Sumapraja S, 2007. Ilmu kandungan. Edisi II. Jakarta: Yayasan Bina Pustaka Sarwono Prawiroharjo, 2005. 338-345.

22.Joedosaputro MS. Ilmu Kandungan. Wiknjosastro $\mathrm{H}$, Saifuddin $\mathrm{AB}$, Rachimhadi T. Editor. Edisi Ke-2. Jakarta: Yayasan Bina Pustaka, 2005.338-345.

23.Suhatno. Tumor Kandungan Picu Wanita Enggan Berhubungan Seks. Suara Surabaya.

http://www.suarasurabaya.net/05/kela nakota.html Last update: Apr 28, 2007. [Diakses pada: 6 Januari 2015].

24.Wachidah, Qonita. Hubungan Hiperplasia Endometrium dengan Mioma Uteri: Studi Kasus Pada Pasien Ginekologi RSUD Prof. DR. Margono Soekardjo Purwokerto. Mandala of Health Journal. Volume 5. Nomor 3, September 2011

25.Parker WH. Etiology, Symtomatology, and Diagnosis of Uterine Myomas. Department of Obstetrics and Gynecology UCLA School of Medicine. California: journal of American Society for Reproductive Medicine. 2007;87:p725-33. 